\title{
Cytogenetic Studies in Withania somnifera (L.) Dun. (Solanaceae)
}

\author{
Mohsina Iqbal and Animesh K. Datta* \\ Department of Botany, Cytogenetics and Plant Breeding Section, Kalyani University, Kalyani-741235, India \\ Received October 31, 2006; accepted November 18, 2006
}

\begin{abstract}
Summary Karyotype analysis (through Image Analyzing System) of Withania somnifera revealed $7\left(2 n=48: 4 \mathrm{~A}_{\mathrm{sm}}^{\mathrm{sc}}+4 \mathrm{~B}_{\mathrm{m}}+14 \mathrm{C}_{\mathrm{m}}+4 \mathrm{D}_{\mathrm{sm}}+2 \mathrm{E}_{\mathrm{st}}+18 \mathrm{~F}_{\mathrm{m}}+2 \mathrm{G}_{\mathrm{sm}}\right)$ morphologically distinct chromosome types. The karyotypes showed prevalence of chromosomes with median primary constrictions. Satellites were associated with short arm of 4A-type chromosomes. Chromosome length in the complement varies from 1.43 to $2.64 \mu \mathrm{m}$. The karyotype was symmetric in nature (TF\%: 42.26). Root tip squash preparations revealed polysomatomy $(2 n=12: 5.8 \%, 2 n=18: 4.8 \%, 2 n=24: 2.9 \%, 2 n=36$ : $25.0 \%, 2 n=48: 57.7 \%$ and $2 n=72: 3.8 \%$ ) with predominance of $2 n=48$ chromosomes. The meiocytes had $2 n=48$ chromosomes always with an average of $23.52 \mathrm{II}+0.95 \mathrm{I}$ per cell. The bivalents formed rods (rods: 20.64 \pm 0.15 , rings: $2.90 \pm 0.17$ ) mostly at diplotene with mean chiasma of $26.45 \pm 0.25$ per cell. A persistent feature in $76.2 \%$ metaphase I cells was the presence of secondary association of chromosomes and the chromosomes tended to form groups of $3(8.0 \%), 6(32.0 \%), 9$ $(16.0 \%)$ and $12(44.0 \%)$. Secondary polyploidy has been attributed as the possible cause of secondary association of chromosomes and the basic chromosome number of the species has been suggested to be $x=12$.
\end{abstract}

Key words Withania somnifera, Karyotype, Meiosis, Secondary chromosome association, Basic chromosome number.

Withania somnifera (L.) Dun. (family Solanaceae) is a much-valued medicinal plant with immense therapeutic applications including anticancerous (Leyon and Kuttan 2004) and antioxidant (Bhattacharya et al. 2001) properties. Cytogenetical studies, which is a prerequisite for genetic improvement in plant species, is restricted to chromosome counts only in W. somnifera and has been found to be variable as $2 n=24$ (Mohan Ram and Kamini 1964), $2 n=48$ (Bhaduri 1933, Gottschalk 1954, Baquar 1967, Bir and Sidhu 1980) and $2 n=72$ (Bir and Neelam 1980). Ray and Jha (2002) reported 21 pairs of bivalent formation in regenerated plants of $W$. somnifera. In view of the fact that chromosome number alone does not provide any cytogenetical criteria, present investigation is aimed to collect cytogenetical information about $W$. somnifera and this research communication reports on the karyotype analysis and meiotic chromosome behaviour which were previously undescribed in the species.

Materials and methods

\section{Plant material}

Seed sample of Withania somnifera (L.) Dun. was collected from Agri-Horticultural Society of India, Kolkata (MPST No.-NHII/XVIII/946, CST No.-NHII/XVIII/596) and plants were raised in the Experimental Garden, Kalyani University. Voucher specimen has been deposited in the Herbarium, Department of Botany, Kalyani University.

*Corresponding author, e-mail: dattaanimesh@gmail.com 


\section{Karyotype analysis}

Root tips were pretreated for $4 \mathrm{~h}$ in aqueous solution of PDB-aesculin at $16 \pm 1{ }^{\circ} \mathrm{C}$, fixed in $1: 3$ propionoalcohol (v/v) overnight and stained in orcein-1(N) HCl mixture (9:1). Slides were prepared using squash technique ( $45 \%$ acetic acid). Suitable metaphase plates ( 5 properly condensed plates) prepared for the species were analyzed through Image Analyzing System as was suggested by Fukui (1986).

Metaphase plates observed under the microscope (Olympus $\mathrm{CH} 40$ ) were photographed using Olympus C-5060 Wide Zoom Camera and these photographs were transferred directly to computer and the chromosome images were analyzed through Micro Image ${ }^{\mathrm{TM}}$ Lite Software (Version 4.0 for Windows, 47N 4015520000515 MAN VG MIX). Chromosome images were measured from 5 plates in pixel unit and were converted to micrometer with reference to a standard scale (stage micrometer) and idiogram was prepared.

The chromosomes were classified as median (m) submedian ( $\mathrm{sm}$ ) and subterminal (st) according to the position of the centromere (Hirahara and Tatuno 1967) and on the basis of chromosome length (long: 2.25 to $3.00 \mu \mathrm{m}$, medium: 1.75 to $<2.25 \mu \mathrm{m}$ and small: $<1.75 \mu \mathrm{m}$ ), centromeric position and the presence of secondary constriction (sc), the chromosomes were morphologically graded into the following type: type A: long submedian chromosomes with satellites, type B: long median chromosomes, type $\mathrm{C}$ : median chromosomes of medium sizes, type $\mathrm{D}$ : submedian chromosomes of medium sizes, type E: medium subtelocentric chromosomes, type F: small median chromosomes, type G: small submedian chromosomes, type $\mathrm{H}$ : small subtelocentric chromosomes. Total chromatin length, TF\% (proportion of short arm in the total chromatin length) and S\% (relative length of shortest chromosome compared to the longest) were also analyzed.

\section{Meiotic analysis}

Flower buds of suitable sizes from 10 randomly selected plants were fixed (5.30 to $6.30 \mathrm{AM}$ ) for $48 \mathrm{~h}$ in Carnoy's fluid at $28 \pm 2{ }^{\circ} \mathrm{C}$ and $1-2$ drops of iron alum were added in the fixative for proper staining. At least 2 changes were given in fixative for removal of oil precipitates. Pollen and pollen mother cells were assessed from anther squash preparations in $1 \%$ propionocarmine solution. Fully stained pollen grains were considered fertile. Meiotic data over the plants has been pooled and represented in the text.

\section{Results and discussion}

\section{Mitotic analysis}

Karyomorphological studies revealed $7\left(2 n=48: 4 \mathrm{~A}_{\mathrm{sm}}{ }^{\mathrm{sc}}+4 \mathrm{~B}_{\mathrm{m}}+14 \mathrm{C}_{\mathrm{m}}+4 \mathrm{D}_{\mathrm{sm}}+2 \mathrm{E}_{\mathrm{st}}+18 \mathrm{~F}_{\mathrm{m}}+\right.$ $2 \mathrm{G}_{\mathrm{sm}}$ ) morphologically distinct chromosome types (Table 1, Figs. 1, 2). The karyotypes showed

Table 1. Karyotypic details in W. somnifera.

\begin{tabular}{ccccc}
\hline \hline Chromosome type & No. of chromosomes & Length $(\mu \mathrm{m})$ & F\% & Centromeric nature \\
\hline A* & 4 & $2.36-2.64$ & $35.20-36.40$ & $\mathrm{sm}$ \\
B & 4 & $2.28-2.35$ & $48.5-50.00$ & $\mathrm{~m}$ \\
C & 14 & $1.86-2.00$ & $43.00-50.00$ & $\mathrm{~m}$ \\
D & 4 & $1.85-1.99$ & $34.60-35.70$ & $\mathrm{sm}$ \\
E & 2 & 1.93 & 24.90 & $\mathrm{st}$ \\
F & 18 & $1.43-1.72$ & $40.00-50.00$ & $\mathrm{~m}$ \\
G & 2 & 1.71 & 33.30 & $\mathrm{sm}$ \\
\hline
\end{tabular}

\footnotetext{
* Chromosomes with satellites.
} 

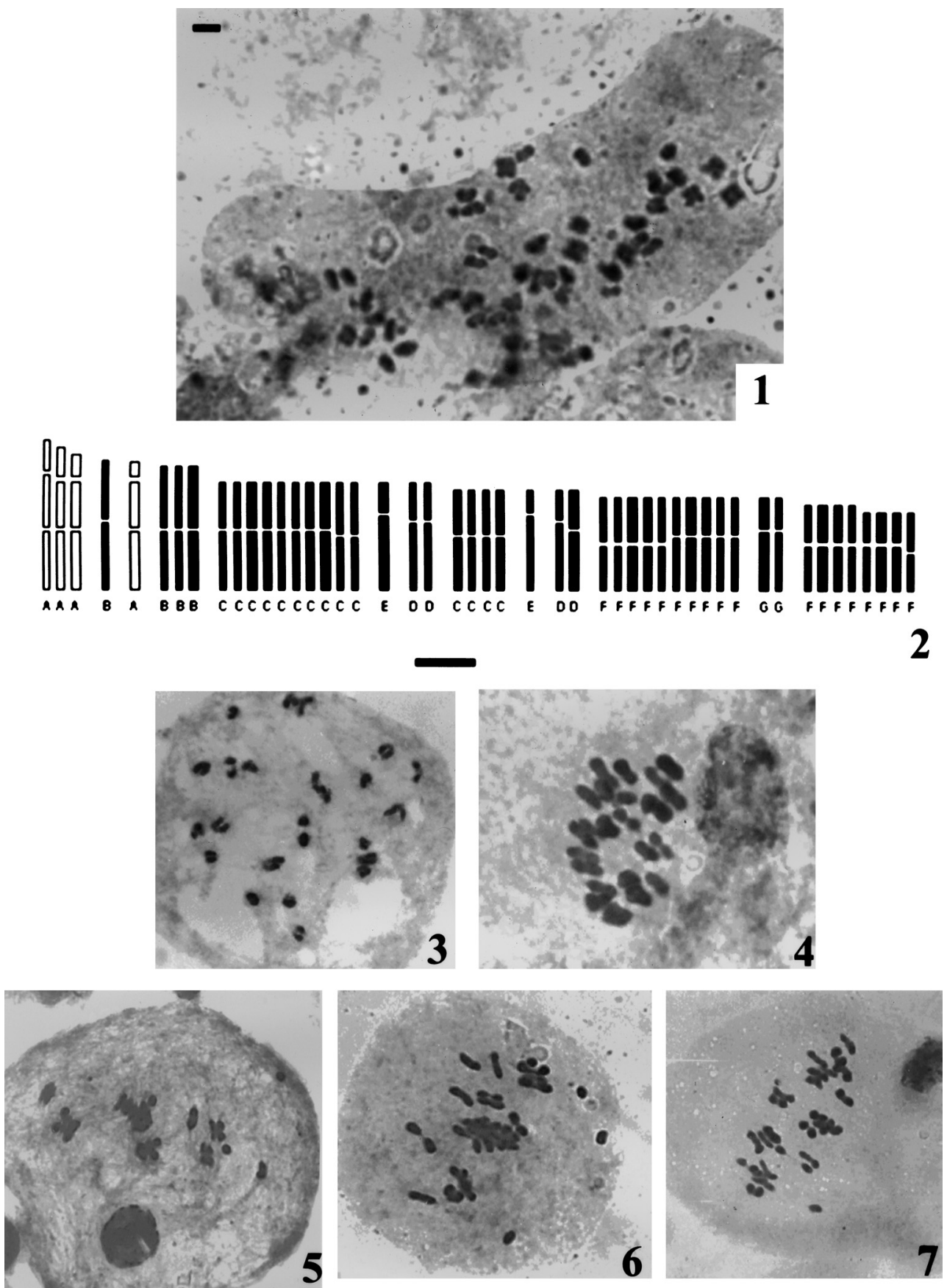

Figs. 1-7. Mitosis (1-2) and meiosis (3-7) in $W$. somnifera. 1) $2 n=48$ chromosomes at metaphase (bar $=3.0 \mu \mathrm{m}$ ). 2) Idiogram showing the chromosome types (bar=1.14 $\mu \mathrm{m}$ ). 3 ) $24 \mathrm{II}$ at diplotene. 4) 24 II at MI. 5-7) Metaphase I configurations showing secondary groupings. 5) 9 group class. 6-7) 12 groups.

prevalence of chromosomes with median (F\%: 40.00 to 50.00) and submedian (F\%: 33.30 to 36.40 ) primary constrictions though there were a few subterminal (F\%: 24.90) chromosomes. Chromosome length was found to vary from $1.43 \mu \mathrm{m}$ to $2.64 \mu \mathrm{m}$. Four chromosomes in A chromosome type were with satellites and the satellites were associated with short arm of the chromosomes. Total 
haploid chromatin length and S\% noted in the species were 45.41 and $64.77 \%$ respectively. The karyotypes were symmetric in nature (TF\%: 42.26). Squash preparations also showed polysomatomy $(2 n=12: 5.8 \%, 2 n=18: 4.8 \%, 2 n=24: 2.9 \%, 2 n=36: 25.0 \%, 2 n=48: 57.7 \%$, and $2 n=72$ : $3.8 \%$ ) with predominance of $2 n=48$ chromosomes ( 104 cells analyzed).

\section{Meiotic analysis}

Meiocytes formed $2 n=48$ chromosomes always (Figs. 3, 4). Predominant chromosomal association had been 24 II in $70.73 \%$ metaphase I (MI) cells (164 cells scored); while the rest had 23 II + 2 I (20.12\%), 22 II + 4 I (5.48\%), 21 II +6 I (0.61\%), 20 II + 8 I (1.22\%), 19 II + 10 I (1.22\%) and $18 \mathrm{II}+12 \mathrm{I}(0.61 \%)$ with an average of $23.52 \mathrm{II}(23.17-23.74)$ and $0.95 \mathrm{I}(0.53-1.67)$ per cell. Bivalents showed prevalence of rod (rods: 20.64 \pm 0.15 , rings: $2.91 \pm 0.17$ ) configuration at diplotene (33 cells scored) with mean chiasma of $26.45 \pm 0.25$ per cell. About $63.85 \%$ anaphase I cells (166 cells analyzed) were cytologically balanced (24/24), while the rest showed unequal separation of chromosomes (23/25) and formed bridges and laggards (1 to 2). Average pollen fertility studied in the species (1939 pollen grains assessed) was 70.25\% (67.9-72.6\%).

\section{Secondary association of chromosomes}

It is interesting to note that bivalents and univalents in the species lie in close proximity without any distinct material connection forming groups (Figs. 5-7) of $3(8.0 \%), 6(32.0 \%), 9(16.0 \%)$ and $12(44.0 \%)$ consistently in $76.2 \%$ MI cells. Such groupings have been referred to as secondary association or secondary pairing of chromosomes (Darlington 1965) and have been used to study basic chromosome number and polyploid nature of plant species (Gupta and Roy 1973, Agarwal 1983, Singh 1986, Sengupta and Datta 2003, Mukherjee and Datta 2005). In the present investigation a total of 9 different types of associations could be analyzed in the group classes of which $18 \mathrm{II}(1)+5 \mathrm{II}(1)+1 \mathrm{II}(1)$ under 3 group class $(6.86 \%)$, $9 \mathrm{II}(1)+4 \mathrm{II}(2)+3 \mathrm{II}(2)+1 \mathrm{II}(1)$ under 6 group class $(11.76 \%), 6 \mathrm{II}(1)+4 \mathrm{II}(2)+3 \mathrm{II}(3)+2 \mathrm{II}(2)+1 \mathrm{II}(3)$ under 9 group class $(9.80 \%)$ and $9 \mathrm{II}(1)+3 \mathrm{II}+1 \mathrm{I}(1)+3 \mathrm{II}(1)+2 \mathrm{II}(1)+1 \mathrm{II}(5)+1 \mathrm{I}(3)$ under 12 (Fig. 6) group class $(24.51 \%)$ were most frequent. Computation of $\chi^{2}$ test revealed heterogeneity between the group classes $\left(\chi^{2}=39.0\right.$ at $3 \mathrm{DF}, p<0.001$ ), thereby suggesting that the chromosomes have assorted themselves more preferentially into certain number of groups (predominantly 12 group class) than they do into others much against random distribution. Although observed cell frequencies of 12 and 6 group classes were higher than expected, only cell frequency of 12 group class was significant and it was verified against the pooled frequency of rest of the classes (observed: 12 group class-55, rest-70; expected 12 group class -31.25 , rest -93.75 ; total $-125 ; \chi^{2}=24.07$ at $1 \mathrm{DF}, p<0.001$ ).

Persistent occurrence of secondary association of chromosomes has suggested secondary polyploid nature of the species and analysis of cytological data revealed that the probable basic chromosome number is 12 . The species might have undergone cytological diploidzation in course of evolution to form diploid like meiotic behaviour.

\section{Acknowledgements}

Financial assistance from Kalyani University and technical help rendered to us from Moumita Mukherjee and Md. Asaf Iqbal are gratefully acknowledged.

\section{References}

Agarwal, P. K. 1983. Secondary association of bivalents in Cissus discolor Blume. Cytologia 48: 577-580. Baquar, S. R. 1967. Cytomorphological studies in the family Solanaceae from West Pakistan. Genetica 38: $388-397$. Bhaduri, P. N. 1933. Chromosome numbers of some solanaceous plants of Bengal. J. Indian Bot. Soc. 14: 56-64. Bhattacharya, A., Ghosal, S. and Bhattacharya, S. K. 2001. Anti-oxidant effect of Withania somnifera glycowithanolides in 
chronic footshock stress-induced perturbations of oxidative free radical scavenging enzymes and lipid peroxidation in rat frontal cortex and striatum. J. Ethnopharmacol. 74: 1-6.

Bir, S. S. and Neelam 1980. In: Chromosome number reports LXIX. Taxon 29: 703-730.

— and Sidhu, M. 1980. Cytological observations on weed flora of orchards of Patiala district of Punjab. In: Bir, S. S. (ed.). Recent Researches in Plant Sciences. Kalyani Publishers, Ludhiana, India. pp. 261-271.

Darlington, C. D. 1965. Recent Advances in Cytology. J. A. Churchilf, London, pp. 786.

Fukui, K. 1986. Standardization of karyotyping chromosomes by a newly developed chromosome image analyzing system. CHIAS. Bull. Natl. Inst. Agrobiol. Resour. 4: 153-176.

Gottschalk, W. 1954. Die Chromosomenstruktur der Solanaceen unter Berucksichtigung phylogeneticscher Fragestellungen. Chromosoma 6: 539-626.

Gupta, P. P. and Roy, S. K. 1973. Primary and secondary chromosome association in Euryle ferox Salisb. Cytologia 38: 645-649.

Hirahara, S. and Tatuno, S. 1967. Cytological studies in Narcissus. I. Karyotype and nucleolinus of Narcissus jonquilla. Cytologia 32: 553-559.

Leyon, P. V. and Kuttan, G. 2004. Effect of Withania somnifera on B16F-10 melanoma induced metastasis in mice. Phytother. Res. 18: 118-122.

Mohan Ram, H. Y. and Kamini, I. 1964. Embryology and fruit development in Withania somnifera Dunal. Phytomorphology 14: 574-587.

Mukherjee, M. and Datta, A. K. 2005. Secondary chromosome associations in Ocimum basilicum L. and Ocimum tenuiflorum L. Cytologia 70: 149-152.

Ray, S. and Jha, S. 2002. Regeneration of Withania somnifera plants. J. Trop. Med. Plants 3: 89-95.

Sengupta, S. and Datta, A. K. 2003. Secondary chromosome associations in control and mutant plant types in Sesamum indicum L. Cytologia 68: 141-145.

Singh, F. 1986. Cytogenetical studies in Petunia. I. Secondary association of bivalents in Petunia parviflora Juss. Cytologia 51: $143-147$. 